Supporting Information

A<smiles>Oc1ccc(/C=C/c2cc(O)cc(O)c2)cc1</smiles>

B<smiles>Oc1cc(O)cc(/C=C/c2ccc(O)c(O)c2)c1</smiles>

Figure S1

Molecular structures of trans-resveratrol (A) and trans-piceatannol (B) 


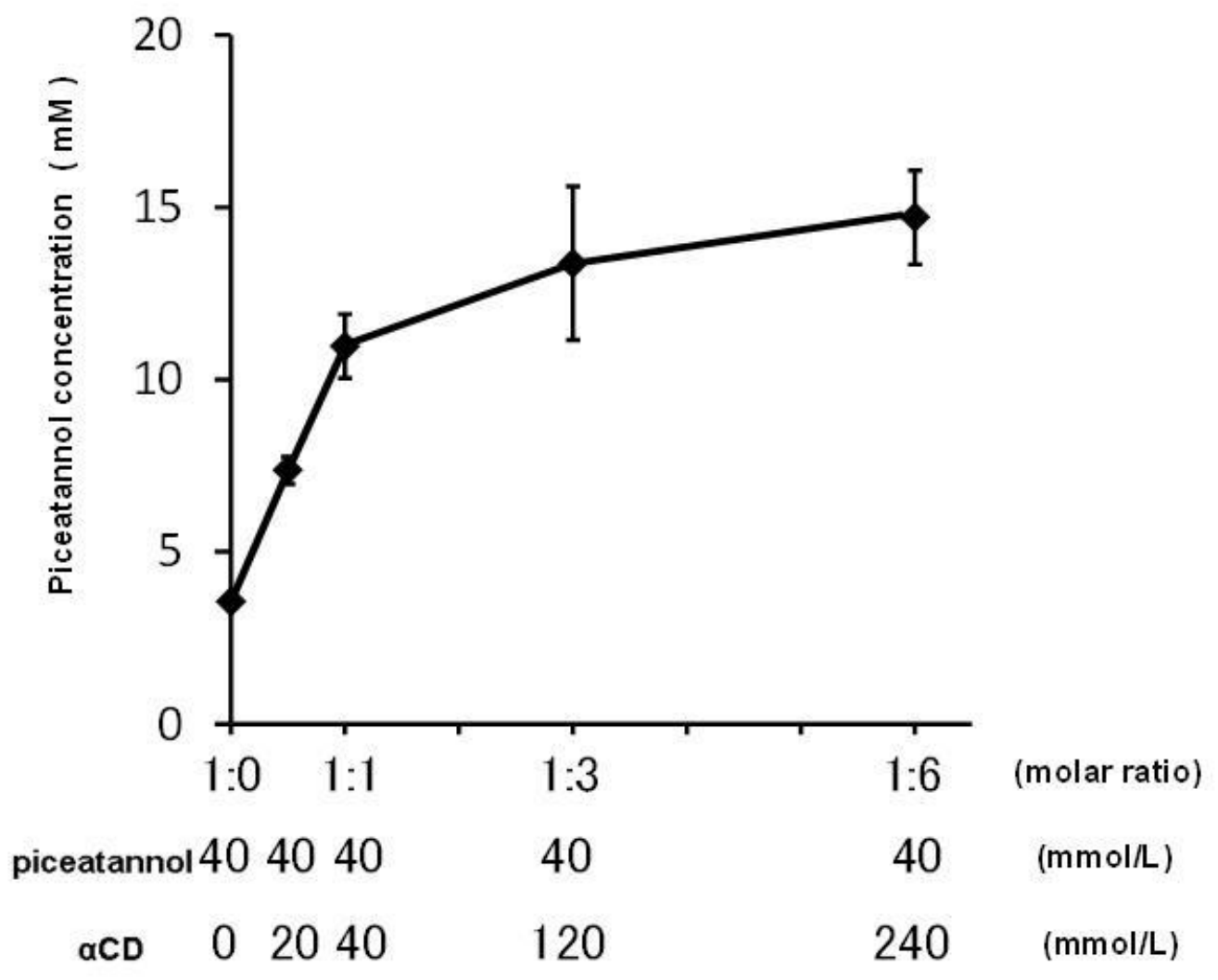

\section{Figure S2}

Aqueous piceatannol solubility as a function of an increasing $\alpha \mathrm{CD}$ molar ratio in $0.5 \%$

$\mathrm{CMC}$ at $25^{\circ} \mathrm{C}$. Piceatannol $(40 \mathrm{mmol} / \mathrm{L})$ in $0.5 \% \mathrm{w} / \mathrm{v} \mathrm{CMC}$ was mixed with various final concentrations of $\alpha \mathrm{CD}(0,20,40,120$ and $240 \mathrm{mmol} / \mathrm{L})$ by vortexing for $15 \mathrm{sec}$ and sonicating 3 times in a $37^{\circ} \mathrm{C}$ water bath for $10 \mathrm{~min}$. Supernatants were collected after centrifugation and filtration through HPLC syringe filters. The supernatants were 
diluted with $84 \%$ mobile phase A $(0.1 \%$ [w/v] phosphoric acid in water) and $16 \%$ mobile phase $\mathrm{B}(0.1 \%[\mathrm{w} / \mathrm{v}]$ phosphoric acid in acetonitrile $)$ as the initial mobile phase and used for HPLC analysis. Samples were measured immediately after preparation. The data represent the mean $\pm \mathrm{SD}$

\section{Table S1}

Time-Dependent Changes in Piceatannol Solubility in Artificial Gastric Juice

\begin{tabular}{cccc}
\hline & \multicolumn{3}{c}{ incubation time $(\mathrm{h})$} \\
\cline { 2 - 4 }$(\mathrm{mM})$ & $3.2 \pm 0.1$ & 0.25 & 1 \\
\hline $\mathrm{Control}$ & $35.0 \pm 0.8$ & $73.8 \pm 0.8$ & $76.0 \pm 3.3$ \\
$\mathrm{H} \alpha \mathrm{CD}$ & $11.5 \pm 0.5$ & $62.4 \pm 2.3$ & $79.9 \pm 0.7$ \\
$\mathrm{M} \alpha \mathrm{CD}$ & $14.3 \pm 0.1$ & $46.4 \pm 2.1$ & $65.3 \pm 1.3$ \\
$\mathrm{~L} \alpha \mathrm{CD}$ & & & \\
\hline
\end{tabular}

$0 \mathrm{~h}=$ immediately after mixing 